\title{
Age-Specific Incidence of Breast Cancer - Are Younger Women at a Higher Risk?
}

\author{
Wolfgang Janni \\ I. Frauenklinik Innenstadt, Klinikum der Ludwig-Maximilians-Universität, Munich, Germany
}

Dear editors,

In industrialized countries, about every 10th woman will develop breast cancer during her life time. Worldwide, and also in Germany, breast cancer is the most common cancer entity in women. The Robert Koch Institute estimates approximately 48,000 new breast cases per year [1]. Unfortunately, a centralized cancer registry is still not available in Germany. However, the region of Greater Munich has been fortunate enough to have a regional cancer registry since 1978. This registry (Chair: Prof. Dr. D. Hoelzel) collects complete pathological and clinical information about new breast cancer patients from the Munich area and parts of Bavaria. In collaboration with clinicians and doctors in private practice, it also gathers reliable follow-up information [2,3].

I would like to comment on breast cancer incidence particularly in younger women. Breast cancer incidence has been rising in Germany until the end of the 1980s. Since the mid 1990s, we notice a decline. Yet, it seems to be a common clinical impression that there is an increasing incidence among younger women. This clinical observation, however, is not at all substantiated by available epidemiological data.

Age-specific incidence refers to the risk for a disease in a certain age group. The age distribution of the German population has changed quite dramatically over the last decades - a phenomenon that can be observed in many western countries. In 1973, young women (and men) in the teens and twenties were a substantial part of the population. Birth rates were high in the 1950s and 1960s, but have since declined, partly due to general availability of hormone-based birth control. Women born before 1970 have now entered an age group where breast cancer slowly becomes an issue. Consequently, age distribution of breast cancer patients currently is strongly affected by the high birth rate of the pre-1970 generations. Thus, what we observe in the clinic may indeed be an increased frequency of younger breast cancer patients under 50 years of age. Howev-

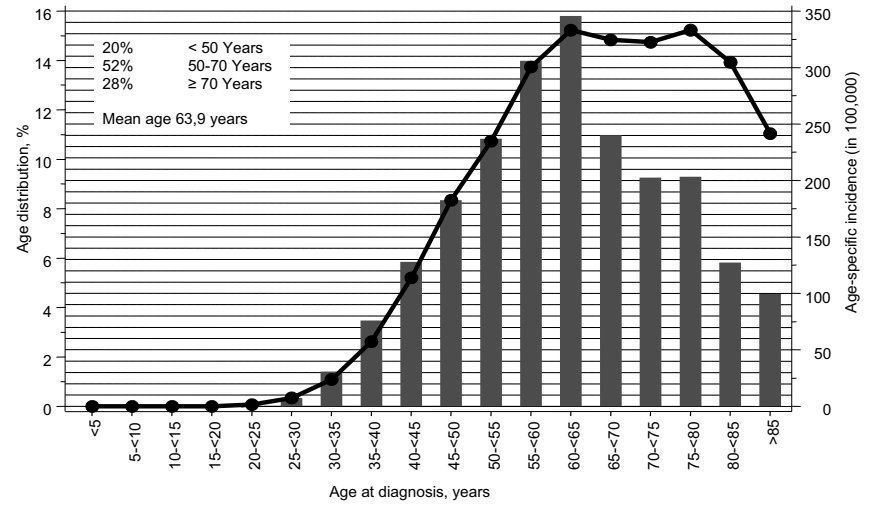

Fig. 1. Regional cancer registry Munich: incidence of breast cancer. Age distribution (bars) and age-specific incidence (dots) 1998-2003 (invasive carcinoma only, $\mathrm{n}=12440$ ).

er, epidemiological evidence suggests that this increased frequency is due to a shift in age distribution in the general population rather than a change in age-specific incidence. This underlines that the risk for developing breast cancer within a certain age group has not changed dramatically.

Age distribution and age-specific incidences, as observed in the Munich area, are depicted in fig. 1. Median age for developing breast cancer is still about 60 years, with an almost symmetrical distribution around this age: Slightly more than half of the patients (52\%) are between 50 and 69 years of age, slightly more than a quarter $(27.8 \%)$ older than 70 years, and about one quarter $(20.2 \%)$ younger than 50 years. Of breast cancer patients younger than 50 years, $10.2 \%$ are between 45 and $50,5.5 \%$ are between 40 and 45 and $3 \%$ are between 35 and 40 years old. In very young women under the age of 35 years, breast cancer is still rare with less than $2 \%$. Only $0.1 \%$ of breast cancers occur under the age of 30 years. Neverthe-

\begin{tabular}{ll}
\hline KARGER & ( ) 2006 S. Karger GmbH, Freiburg \\
Fax +49 7614520714 & Accessible online at: \\
$\begin{array}{l}\text { E-mail Information@Karger.de } \\
\text { www.karger.com }\end{array}$ & www.karger.com/brc
\end{tabular}

PD Dr. med. Wolfgang Janni

Klinikum der Ludwig-Maximilians-Universität

I. Frauenklinik Innenstadt

Maistr. 11, 80337 München, Germany

Tel. +49 89 5160-4250, Fax -4186

E-mail Wolfgang.Janni@med.uni-muenchen.de 
less, breast cancer in such young women should always caution clinicians to ask about family history and consider specific risk counseling and genetic testing.

In concordance with the age-specific incidence, age-specific mortality is increasing with age. In countries with more centralized cancer registries, such as USA or England, a substantial decline of overall breast cancer mortality has been observed since the 1980s [4]. This may partly be explained by better early detection programs and partly by better adjuvant systemic therapies.

\section{References}

1 Brenner H, Stegmaier C, Ziegler H: Long-term survival of cancer patients in Germany achieved by the beginning of the third millennium. Ann Oncol 2005; 16:981-986.

2 Engel J, Kerr J, Schlesinger-Raab A, Sauer H, Holzel D: Quality of life following breast-conserving therapy or mastectomy: results of a 5-year prospective study. Breast J 2004;10:223-231.

3 Engel J, Kerr J, Schlesinger-Raab A, Eckel R, Sauer H, Holzel D: Comparison of breast and rectal cancer patients' quality of life: results of a four year prospective field study. Eur J Cancer Care (Engl) 2003;12:215-223.

4 Early Breast Cancer Trialists' Collaborative Group (EBCTCG): Effects of chemotherapy and hormonal therapy for early breast cancer on recurrence and 15-year survival: an overview of the randomised trials. Lancet 2005;365: 1687-1717. 